\title{
The Prevalence of Nocturia and Nocturnal Polyuria: Can New Cutoff Values Be Suggested According to Age and Sex?
}

\author{
Ali Ersin Zumrutbas ${ }^{1}$, Ali Ihsan Bozkurt ${ }^{2}$, Okan Alkis ${ }^{1}$, Cihan Toktas ${ }^{1}$, Bulent Cetinel ${ }^{3}$, Zafer Aybek ${ }^{1}$ \\ ${ }^{1}$ Department of Urology, Pamukkale University School of Medicine, Denizli, Turkey \\ ${ }^{2}$ Department of Public Health, Pamukkale University School of Medicine, Denizli, Turkey \\ ${ }^{3}$ Department of Urology, Istanbul University Cerrahpasa School of Medicine, Istanbul, Turkey
}

Purpose: The aims of this study were to assess the prevalence of nocturia and nocturnal polyuria (NP) and to define new cutoff values according to age and sex for both conditions.

Methods: Data from a population-based prevalence survey conducted among a random sample of 2,128 adults were analyzed in this study. Participants were requested to fill out a questionnaire including the International Continence Society (ICS) definitions of lower urinary tract symptoms and the International Consultation on Incontinence Questionnaire - Short Form. Additionally, a 1-day bladder diary was given to each individual. The participants were divided into 5 age groups. The prevalence of nocturia was calculated based on definitions of nocturia as $\geq 1$ voiding episodes, $\geq 2$ episodes, and $\geq 3$ episodes. NP was evaluated according to the ICS definition. The mean \pm standard errors and 95th percentile values were calculated in each group as new cutoff values for NP.

Results: The prevalence of nocturia was estimated as $28.4 \%, 17.6 \%$, and $8.9 \%$ for $\geq 1, \geq 2$, and $\geq 3$ voiding episodes each night, respectively. When nocturia was defined as 2 or more voiding episodes at night, the prevalence decreased significantly. The mean NP index was $29.4 \% \pm 15.0 \%$ in men and $23.1 \% \pm 11.8 \%$ in women. For the age groups of $<50$ years, $50-59$ years, and $\geq 60$ years, the new cutoff values for the diagnosis of NP were calculated as $48 \%, 69 \%$, and $59 \%$ for men and $41 \%, 50 \%$, and $42 \%$ for women, respectively.

Conclusions: We found that the definition of nocturia was still controversial and that waking up once for voiding might be within the normal spectrum of behavior. The definition of NP should be modified, and new cutoff values should be defined using the data presented in our study and in other forthcoming studies.

Keywords: Nocturia; Polyuria; Prevalence; Terminology

- Research Ethics: The local ethics committee and the review board of Pamukkale University School of Medicine approved the study (approval number: 1208)

- Conflict of Interest: No potential conflict of interest relevant to this article was reported.

\section{INTRODUCTION}

Nocturia is one of the most prevalent and bothersome lower urinary tract symptoms (LUTS) [1]. According to several previ- ous studies, nocturia has detrimental effects on quality of life (QoL) and overall health, mainly due to sleep disturbances [24]. According to the 2002 International Continence Society (ICS) definition, nocturia is defined as waking at night to void,

Corresponding author: Ali Ersin Zumrutbas (iD http://orcid.org/0000-0001-5933-402X Department of Urology, Pamukkale University School of Medicine, Denizli, Turkey

E-mail: alizumrut@yahoo.com / Tel: +90-532-789-8961 / Fax: +90-258-296-6001

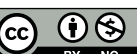

This is an Open Access article distributed under the terms of the Creative Commons Attribution Non-Commercial License (http://creativecommons.org/licenses/by-nc/4.0/) which permits unrestricted non-commercial use, distribution, and reproduction in any medium, provided the original work is properly cited.

Submitted: March 3, 2016 / Accepted after revision: April 4, 2016 
which applies to any number of voiding episodes at any time during the night [5]. This definition, however, lacks sensitivity regarding how bothersome the symptom is. Some authors have suggested that getting up to void once a night may be normal, that most people who void less than 2 times per night generally do not suffer from their condition, and that nocturia has been shown to be associated with more serious consequences when nocturnal voiding occurs $\geq 2$ times on a regular basis $[4,6]$.

Nocturnal polyuria (NP) is defined as the production of an abnormally large volume of urine during sleep. According to the most recent ICS definition, NP is present when an increased proportion of the 24-hour output occurs at night [5]. Frequency volume charts are used to determine the presence of NP. The most widely used index is the NP index (NPI), which is the ratio of nocturnal urine production (NUP) to 24-hour urine production expressed as a percentage [7]. Rembratt et al. [8] classified the definitions of NP as absolute, relative, and functional. Asplund et al. [9] proposed an absolute definition (NUP $\geq 0.9$ $\mathrm{mL} / \mathrm{min}$ ), which they later proposed modifying to $1.3 \mathrm{~mL} / \mathrm{min}$. Other definitions also have been presented by different authors [10-12].

It has been pointed out that the suggested definitions of NP, which refer to the day-to-night ratio in urine production, are not based on normal distributions and have not been properly validated [13]. Similarly, the panelists at the 2012 New England Research Institute (NERI) Nocturia Advisory Conference agreed that more research is required to determine appropriate population-based norms for NP, as well as to set a more reliable threshold for nocturia [4]. Additional concerns have been reported at the Nocturia Think Tank (NTT) panel in 2014 [14]. Therefore, the definitions of both nocturia and NP are controversial, as is the cutoff point for NP. In this study, we aimed to assess the prevalence of both conditions and to define new cutoff values for nocturia and NP in the population.

\section{MATERIALS AND METHODS}

The data analyzed in this study were drawn from a populationbased survey of the prevalence of LUTS, overactive bladder, and urinary incontinence that was conducted among a random sample of 2,128 women and men aged $\geq 18$ years. The selection of the participants was described in detail in our recently published study [15]. The local ethics committee and the review board of Pamukkale University School of Medicine (approval number: 1208) approved the study. Participants were requested to fill out a questionnaire including the ICS definitions of LUTS, including increased daytime frequency, nocturia, urgency, slow stream, splitting or spraying, intermittent stream, hesitancy, straining, terminal dribble, feeling of incomplete emptying, and postmicturition dribble, as well as the International Consultation on Incontinence Questionnaire - Short Form (ICIQ-SF). Additionally, a bladder diary was given to each individual to fill out for a 24 -hour period.

The study was mainly conducted at family health centers, and the primary care physicians and their assistant nurses had previously been trained in obtaining data for the study. The assessment of height, weight, body mass index, vital signs, and urinalysis with a dip-stick test was also performed by these staff members. Participants with a positive dip-stick test for nitrites were excluded from the study. The individuals who agreed to participate in the study were instructed by the staff about the study questionnaires and how to complete the bladder diaries accurately.

The participants were suggested to empty their bladder on the first morning, and after emptying their bladder, to record all data about fluid intake and voiding with the event time in hours and minutes. They were requested to write down the volume of intake, voiding time and volume, and times of sleeping and waking up. Special duck-shaped scaled urine containers were provided for this study and given to each participant to measure and record voiding volumes accurately. The recording of micturition ended with the first voiding after waking up the next morning. The volume of this voiding was recorded as the last voiding.

In the participants who did not report any nocturia or record any voiding during the night, the voided volume the next morning was recorded as the nocturnal urine volume (NUV). A 24-hour urine output of more than $40 \mathrm{~mL} / \mathrm{kg}$ was considered polyuria. The prevalence of NP was also calculated according to previous definitions, which were presented above.

The participants were divided into 5 age groups (18-29 years, $30-39$ years, $40-49$ years, $50-59$ years, and $\geq 60$ years). The prevalence of nocturia was calculated using the ICS definition of $\geq 1$ voiding episode per night. We also classified the respondents with $\geq 2$ and $\geq 3$ nocturnal voiding episodes per night into separate groups for comparison and further analysis.

To determine a previously undefined reference range or value, it is common to establish the reference range as including all available data within the 95th percentile as a way of distinguishing normal from high or abnormal values. This is a prediction 
rather than a strict definition of a constant, and in a normally distributed sample this corresponds to the mean plus 1.645 times the standard deviation (SD). The upper limit of this reference range is usually used as the cutoff point [7]. In our study, the mean \pm standard error (SE) and 95th percentiles (mean+ $[1.645 \times \mathrm{SD}])$ were calculated in each group to define the $\mathrm{NP}$ cutoff. Statistical analysis was performed using SPSS ver. 17.0 (SPSS Inc., Chicago, IL, USA).

Table 1. Characteristics and comorbidities of the study population

\begin{tabular}{lccc}
\hline Variable & $\begin{array}{c}\text { Men } \\
(\mathrm{n}=636)\end{array}$ & $\begin{array}{c}\text { Women } \\
(\mathrm{n}=919)\end{array}$ & $\begin{array}{c}\text { Total } \\
(\mathrm{n}=1,555)\end{array}$ \\
\hline Sex & 40.9 & 59.1 & 100 \\
Age group (yr) & & & \\
18-29 & 18.3 & 22.3 & 20.7 \\
$30-39$ & 23.8 & 28.6 & 26.6 \\
40-49 & 22.9 & 20.8 & 21.6 \\
50-59 & 18.6 & 15.2 & 16.6 \\
$\geq 60$ & 16.4 & 13.1 & 14.5 \\
Comorbidities & & & \\
Hypertension & 15.3 & 15.7 & 15.5 \\
Diabetes mellitus & 12.4 & 10.2 & 11.0 \\
Hyperlipidemia & 6.5 & 4.9 & 5.5 \\
COPD or asthma & 2.9 & 3.6 & 3.4 \\
Cerebrovascular accident & 1.6 & 0.2 & 0.7 \\
Thyroid diseases & 0.7 & 7.5 & 5 \\
Coronary artery disease & 5.9 & 2.6 & 3.7 \\
Psychiatric diseases & 1.0 & 2.0 & 1.6 \\
Medications & 38.0 & 43.2 & 41.4 \\
Diuretics & 6.5 & 6.6 & 6.5 \\
Antihyperlipidemics & 4.2 & 3.1 & 3.5 \\
Antihypertensives & & & \\
Antidiabetics/insulin & 6.8 & 6.2 & 6.6 \\
Antidepressants & 0.3 & 3.1 & 2.1 \\
Asthma or COPD medications & 1.6 & 0.5 & 0.9 \\
Thyroid replacement & 0.3 & 4.6 & 3.0 \\
\hline
\end{tabular}

Values are presented as percentage.

COPD, chronic obstructive pulmonary disease.

a)Antihypertensives other than antidiuretics.

\section{RESULTS}

Of the 2,128 people surveyed, 1,555 (74\%) agreed to participate in the study, and of those, 856 (55\%) filled in the bladder diaries accurately and returned them. Of the missing diaries, 570 $(81.5 \%)$ were not filled in or returned. We could not read the handwriting in 26 diaries (3.7\%), 42 (6\%) had missing sleeping or waking times, and $61(8.7 \%)$ had missing intake or voided volumes. We did not find a significant difference in subscale scores regarding ICS definitions, symptom severity, and ICIQSF parameters between responders and others $(\mathrm{P}>0.05)$.

The characteristics of the study population, comorbidities, and medications are given in Table 1, and selected bladder diary data are presented in Table 2 . The prevalence of nocturia in each group is given in Table 3 . The prevalence of nocturia significantly increased with age. When nocturia was defined as 2 or more voiding episodes at night, its prevalence decreased significantly (Fig. 1).

In men, the mean \pm SD NPI values for the age groups $<50$ years, $50-59$ years, and $\geq 60$ years were $23.3 \% \pm 13.4 \%$, $29.3 \% \pm 17.1 \%$, and $33.2 \% \pm 13.3 \%$, respectively. The mean \pm SD NPI values for the same age groups were $22.2 \% \pm 11.5 \%$, $25.5 \% \pm 13.0 \%$, and $22.7 \% \pm 10.9 \%$ in women. NP increased with age in men, but no linear correlation with age was observed in women (Fig. 2). When the 95th percentile was used to distinguish normal from abnormal values, the cutoff values for the diagnosis of NP in the age groups of $<50$ years, $50-59$ years and $\geq 60$ years were $48 \%, 69 \%$, and $59 \%$ for men and $41 \%$, $50 \%$, and $42 \%$ for women, respectively.

In order to compare our findings with those of previous studies, a similar calculation was performed regarding the older definitions of NP, and the cutoff value (95th percentile) for the nocturia index (NI) was 2.6 for men and 2.5 for women. The same cutoff for NUP (mL/hr) was 159 for men and 137 for

Table 2. Bladder diary data of the study group

\begin{tabular}{lccr}
\hline Bladder diary data & Men $(\mathrm{n}=307)$ & Women $(\mathrm{n}=549)$ & Total $(\mathrm{n}=856)$ \\
\hline Fluid intake $(\mathrm{mL})$ & $2,358 \pm 938(400-6,100)$ & $2,248 \pm 988(350-6,600)$ & $2,287 \pm 971(350-6,600)$ \\
24-Hour urine output $(\mathrm{mL})$ & $1,568 \pm 863(400-6,840)$ & $1,747 \pm 1,132(290-8,900)$ & $1,682 \pm 1,046(290-8,900)$ \\
24-Hour voiding frequency & $6.6 \pm 2.5(2-15)$ & $7.8 \pm 3.0(2-31)$ & $7.4 \pm 2.9(2-31)$ \\
Nighttime urine output & $492 \pm 326(100-1,400)$ & $446 \pm 307(60-1,500)$ & $460 \pm 312(60-1,500)$ \\
Maximum voided volume & $382 \pm 167(100-850)$ & $404 \pm 185(100-1,200)$ & $396 \pm 179(100-1,200)$ \\
Nocturia index & $1.37 \pm 0.71(0.22-3.00)$ & $1.25 \pm 0.70(0.20-4.00)$ & $1.29 \pm 0.71(0.20-4.00)$ \\
\hline
\end{tabular}

Values are presented as mean \pm standard deviation (range). 
Table 3. Prevalence of nocturia in each age group according to the International Continence Society definition and alternative definitions

\begin{tabular}{|c|c|c|c|c|c|c|}
\hline \multirow{2}{*}{ Definition } & \multicolumn{6}{|c|}{ Age group (yr) } \\
\hline & $18-29$ & $30-39$ & $40-49$ & $50-59$ & $\geq 60$ & Total \\
\hline \multicolumn{7}{|l|}{ Men } \\
\hline Nocturia as $\geq 1$ voiding episode $\mathrm{e}^{\mathrm{a})}$ & 5.2 & 10.6 & 23.4 & 34.7 & 57.7 & 24.8 \\
\hline Nocturia as $\geq 2$ voiding episodes & 0 & 3.3 & 13.8 & 22.9 & 48.1 & 16.1 \\
\hline Nocturia as $\geq 3$ voiding episodes & 0 & 1.3 & 6.9 & 9.3 & 27.9 & 8.2 \\
\hline \multicolumn{7}{|l|}{ Women } \\
\hline Nocturia as $\geq 1$ voiding episode $\mathrm{e}^{\mathrm{a})}$ & 19.1 & 21.5 & 35.3 & 43.9 & 50.0 & 31.0 \\
\hline Nocturia as $\geq 2$ voiding episodes & 11.8 & 11.1 & 22.1 & 28.1 & 30.0 & 18.6 \\
\hline Nocturia as $\geq 3$ voiding episodes & 5.4 & 5.4 & 11.6 & 15.8 & 14.2 & 9.4 \\
\hline \multicolumn{7}{|l|}{ All } \\
\hline Nocturia as $\geq 1$ voiding episode $\mathrm{a}^{\mathrm{a})}$ & 14.1 & 17.5 & 30.1 & 39.7 & 53.6 & 28.4 \\
\hline Nocturia as $\geq 2$ voiding episodes & 7.5 & 8.3 & 18.5 & 25.7 & 38.4 & 17.6 \\
\hline Nocturia as $\geq 3$ voiding episodes & 3.4 & 3.9 & 9.6 & 12.8 & 20.5 & 8.9 \\
\hline
\end{tabular}

Values are presented as percentage.

${ }^{a)}$ International Continence Society definition.
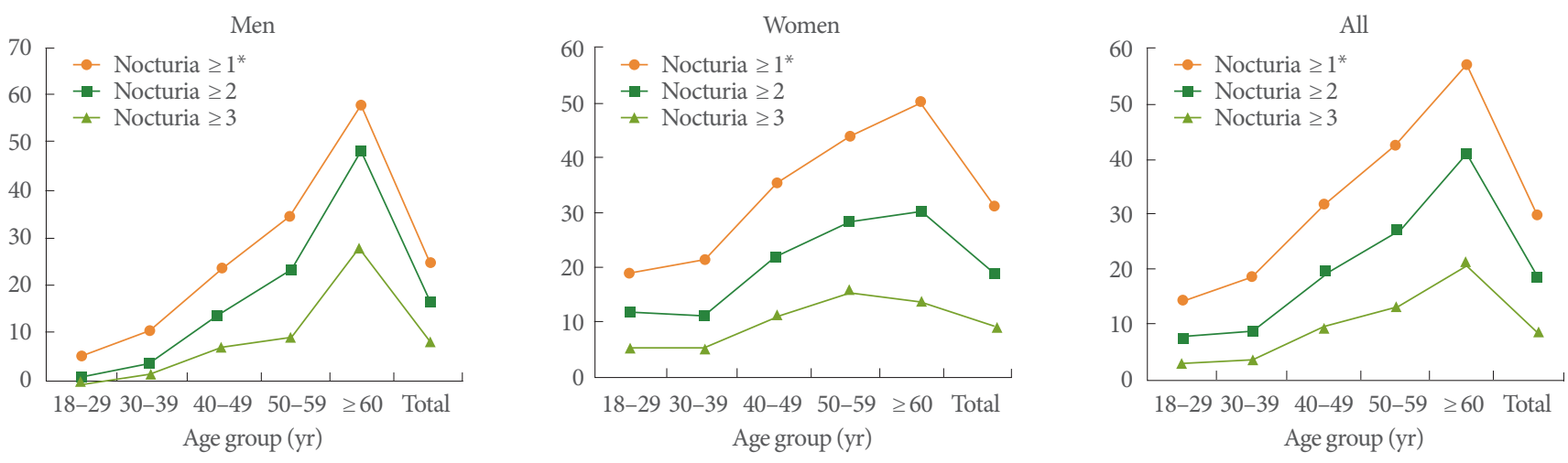

Fig. 1. The prevalence (\%) of nocturia in age groups defined according to various cutoffs for nocturia (in terms of number of voiding episodes per night). ${ }^{*}$ International Continence Society definition.

women. When NUV was adjusted for body weight, the 95th percentile values were $16.4 \mathrm{~mL} / \mathrm{kg}$ and $14.8 \mathrm{~mL} / \mathrm{kg}$ for men and women, respectively.

The prevalence of NP according to the current ICS definition was $44 \%$ in participants under 65 years of age and $31.3 \%$ in participants aged 65 years or older. The prevalence of NP according to the older definitions was also calculated and found to be between $14.6 \%$ and $42.4 \%$ (Table 4 ).

\section{DISCUSSION}

Although the consensus ICS definition employs a nocturia cutoff of 1 voiding episode per night, some authors have suggested that a cutoff of 2 voiding episodes per night might be more clinically relevant and better correlated to QoL impairment [16].
Our results showing a significant decrease in the prevalence of nocturia according to the latter definition support this suggestion. Studies of the effects of nocturia on QoL have shown that most people with less than 2 voiding episodes per night generally have only minimal bother from the condition, and that nocturia is more likely to have more serious consequences only when $\geq 2$ voiding episodes per night occur on a regular basis [6]. Although nocturia literally refers to waking up to void, as defined by the ICS, a certain cutoff point is needed when it is used to describe a symptom or a clinical disease that has known consequences for health and health-related QoL. The current definition may include individuals who do not consider their nocturia bothersome [14]. Alternatively, new terms such as "bothersome nocturia" may be used to distinguish nocturia as a disease from the term used for waking up to void. 

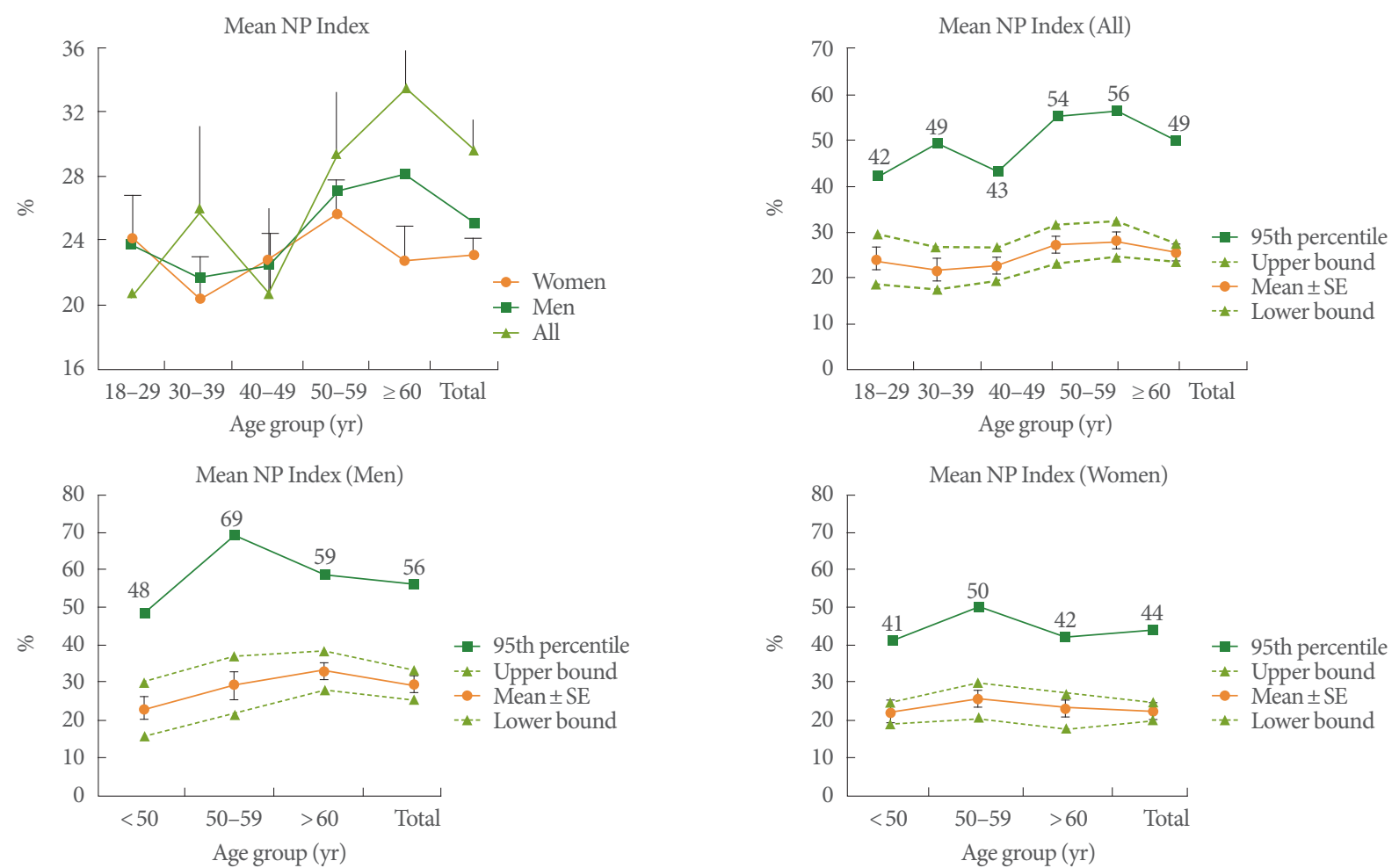

Fig. 2. Mean \pm standard error (SE) NPI values with 95\% confidence intervals and 95th percentiles for all age groups. NP, nocturnal polyuria; NPI, nocturnal polyuria index.

Table 4. Prevalence of nocturnal polyuria in our population according to the definitions in the previous literature

\begin{tabular}{llcccc}
\hline Study & \multicolumn{1}{c}{ Definition } & Study group & Men (\%) & Women (\%) & Overall (\%) \\
\hline Asplund et al. [9] & NUP $\geq 54 \mathrm{~mL} / \mathrm{hr}$ & Men $(50-78 \mathrm{yr})$ & 42.2 & 42.4 & 42.3 \\
Asplund et al. [9] & NUP $\geq 78 \mathrm{~mL} / \mathrm{hr}$ & Men $(50-78 \mathrm{yr})$ & 26.6 & 22.9 & 24.0 \\
Homma et al. [10] & NUP $\geq 10 \mathrm{~mL} / \mathrm{kg}$ & All $(20-89 \mathrm{yr})$ & 17.7 & 16.7 & 17.0 \\
Blanker et al. [11] & NUP $\geq 90 \mathrm{~mL} / \mathrm{hr}$ & All $(60-74 \mathrm{yr})$ & 18.8 & 14.6 & 15.9 \\
Weiss et al. [12] & NI $>1.5$ & Men (65-68 yr) & 35.3 & 28.0 & 30.2 \\
\hline
\end{tabular}

NUP, nocturnal urine production; NI, nocturia index (the ratio of NUP to functional bladder capacity).

a) Alternative definition by Asplund et al. [9] (NUP $\geq 1.3 \mathrm{~mL} / \mathrm{min}$ ).

Population-based studies have shown age to be the most important risk factor for nocturia [17]. In our study, the prevalence of nocturia increased with age in both sexes. Our results also confirmed those of previous studies that showed sex to have a significant impact, with the prevalence of nocturia was generally greater in women among young adults, but greater in men among the elderly [17].

The ICS standardization report on terminology states that the normal range of NUP differs with age and that normal ranges remain to be defined [13]. A gap exists between the age groups that have been defined (young adults and adults $>65$ years) and there is a large range between the defined cutoff values. For example, what should the NP cutoff be for a man aged 63 years? Should the answer be $20 \%, 33 \%$, or somewhere between these 2 cutoff values?

In a normally distributed dataset, if the normal and abnormal values are not known and need to be calculated, the 95th percentile is a common reference point to distinguish abnormal values from normal. In a recent study, this method was used to determine the cutoff in a normally distributed sample of 894 volunteers without urological complaints, and a NPI of more than $53 \%$ was advocated as the NP cutoff [7]. The utility of this 
method, however, was criticized in an editorial comment on the same article.

In our study, which was conducted on a population-based sample of 856 people, we found a mean NPI of $29.4 \%$ in men and $23.1 \%$ in women. We suggest that the NP cutoffs corresponding to the 95th percentile for the age groups of $<50$ years, $50-59$ years and $\geq 60$ years should be $48 \%, 69 \%$, and $59 \%$ for men and $41 \%, 50 \%$, and $42 \%$ for women, respectively. We included all participants and did not repeat the analysis for those without nocturia or polyuria. In a recent study, further analysis of the subgroup without nocturia and polyuria did not reveal any significant differences [7]. Our study is the first to use the 95th percentile to define a cutoff for NP in a population-based study. Our results confirm the findings of van Haarst and Bosch [7] who used the same method in asymptomatic volunteers who were recruited from hospital staff, their families, and patient families. However, our suggestions should not be perceived as strict definitions. Further studies validating or modifying our cutoff values would clarify this issue.

The 2012 NERI Nocturia Advisory Conference report presented a PubMed search that yielded 58 studies containing 16 definitions of NP. This report concluded that even the most widely accepted definition of NP, from the 2002 ICS report, was lacking in scientific rigor [4]. Our study is the first to show high prevalence rates in the population using the current definition of NP. According to the latest and the most widely accepted definition of NP, the prevalence of NP in our population was $44 \%$ in adults $<65$ years and $31.3 \%$ in adults $\geq 65$ years of age. Since $90 \%$ of our adult population was younger than 65 years, more than $40 \%$ of our adult population would be diagnosed with NP if the current terminology is used. This observation was the main incentive for us to conduct this study. The estimates used in the ICS terminology report for NP were based on very small sample sizes: 18 subjects in the study used to develop the young adult cutoff and 45 subjects in the study used to develop the cutoff for the elderly $[4,18,19]$. We suggest that a cutoff should neither deprive certain patients of effective treatment that they actually need nor cause overtreatment for healthy people, exposing them to the side effects of certain medications. The criterion of the 95th percentile, which was used for these calculations, can be modified according to further studies calculating the sensitivity and specificity of the defined cutoffs. In the latest NTT report, it was stated that the NPI (33\%) should not be used without correcting for age and excluding 24-hour polyuria.
The alternative definitions of NP suggested in the past also resulted in high prevalence rates of NP. According to the definition of Blanker et al. (NUP $\geq 90 \mathrm{~mL} / \mathrm{hr}$ ), $15.9 \%$ of our population had NP [11]. The Krimpen study evaluated this definition and estimated that $28 \%$ of men with nocturia had NP, compared with $8 \%$ of those without nocturia [20]. Asplund et al. [9] defined NP as the rate of NUP $\geq 0.9 \mathrm{~mL} / \mathrm{min}$ at night. However, the authors suggested that a lower limit of NUP $\geq 1.3 \mathrm{~mL} / \mathrm{min}$ might be more appropriate for selection purposes in future trials $[8,9]$. When we applied the suggested threshold to our study population, the prevalence of NP was $26.6 \%$ in men and $22.9 \%$ in women. Another definition of NP, NUP adjusted for body weight ( $>10 \mathrm{~mL} / \mathrm{kg}$ ), was suggested by Homma et al. [10]. This threshold was chosen based on the upper quartile from a sample of 67 adults without any LUTS. In our study population, when we calculated the cutoff for the 95th percentile, it was $16.4 \mathrm{~mL} / \mathrm{kg}$ for men and $14.8 \mathrm{~mL} / \mathrm{kg}$ for women.

Another way of defining NP is NI, which was defined by Weiss et al. as the NUV divided by the largest single voided volume (functional bladder capacity) from a 24-hour diary [8,12]. A threshold of 1.5 was suggested by the authors. When we applied this threshold to our study population, the overall prevalence of NP was $30.2 \%$. When we calculated the threshold for NI based on the 95th percentile, the new cutoff values were 2.6 for men and 2.5 for women.

Our study also had certain limitations. We used a 1-day bladder diary in our study, although a 3-day diary would have been ideal. We did not consider this to be a major limitation because this study was planned as a part of a prevalence study rather than a clinical trial. Furthermore, only $55 \%$ of the participants filled out the bladder diaries accurately, and this rate might have decreased if the diary period were to have been increased. Since we focused on the definitions of nocturia and NP, we did not analyze the determinants or predictors of those conditions, although we had a large database from our population-based prevalence study. Nevertheless, we suggest that the present study fills a scientific gap in this field; this gap was also pointed out by the NERI and NTT panelists, who encouraged more research to determine population-based norms for NP and thresholds for nocturia $[13,14]$.

In this study, we showed that the definition of nocturia remains controversial and that waking up once for voiding might be within the normal spectrum of behavior. Thus, the definition of nocturia should be modified to be waking up 2 or more times at night to void. When applied to a large population sample, the 
current definition and the past definitions of NP resulted in high prevalence rates. Therefore, the definition of NP should be modified, and new cutoff values should be defined using the data of the present study and other forthcoming studies.

\section{REFERENCES}

1. Bosch JL, Weiss JP. The prevalence and causes of nocturia. J Urol 2010;184:440-6.

2. Asplund R, Marnetoft SU, Selander J, Akerström B. Nocturia in relation to somatic health, mental health and pain in adult men and women. BJU Int 2005;95:816-9.

3. Kupelian V, Fitzgerald MP, Kaplan SA, Norgaard JP, Chiu GR, Rosen RC. Association of nocturia and mortality: results from the Third National Health and Nutrition Examination Survey. J Urol 2011;185:571-7.

4. Weiss JP, Blaivas JG, Blanker MH, Bliwise DL, Dmochowski RR, Drake M, et al. The New England Research Institutes, Inc. (NERI) Nocturia Advisory Conference 2012: focus on outcomes of therapy. BJU Int 2013;111:700-16.

5. van Kerrebroeck P, Abrams P, Chaikin D, Donovan J, Fonda D, Jackson S, et al. The standardisation of terminology in nocturia: report from the Standardisation Sub-committee of the International Continence Society. Neurourol Urodyn 2002;21:179-83.

6. Coyne KS, Zhou Z, Bhattacharyya SK, Thompson CL, Dhawan R, Versi E. The prevalence of nocturia and its effect on health-related quality of life and sleep in a community sample in the USA. BJU Int 2003;92:948-54.

7. van Haarst EP, Bosch JL. A cutoff value based on analysis of a reference population decreases overestimation of the prevalence of nocturnal polyuria. J Urol 2012;188:869-73.

8. Rembratt A, Norgaard JP, Andersson KE. What is nocturnal polyuria? BJU Int 2002;90 Suppl 3:18-20.

9. Asplund R, Sundberg B, Bengtsson P. Desmopressin for the treatment of nocturnal polyuria in the elderly: a dose titration study. $\mathrm{Br}$ J Urol 1998;82:642-6.

10. Homma Y, Yamaguchi O, Kageyama S, Nishizawa O, Yoshida M,
Kawabe K. Nocturia in the adult: classification on the basis of largest voided volume and nocturnal urine production. J Urol 2000; 163:777-81.

11. Blanker MH, Bernsen RM, Bosch JL, Thomas S, Groeneveld FP, Prins Ad, et al. Relation between nocturnal voiding frequency and nocturnal urine production in older men:a population-based study. Urology 2002;60:612-6.

12. Weiss JP, Blaivas JG, Stember DS, Chaikin DC. Evaluation of the etiology of nocturia in men: the nocturia and nocturnal bladder capacity indices. Neurourol Urodyn 1999;18:559-65.

13. Weiss JP, Bosch JL, Drake M, Dmochowski RR, Hashim H, Hijaz A, et al. Nocturia Think Tank: focus on nocturnal polyuria: ICI-RS 2011. Neurourol Urodyn 2012;31:330-9.

14. Bosch JL, Everaert K, Weiss JP, Hashim H, Rahnamải MS, Goessaert AS, et al. Would a new definition and classification of nocturia and nocturnal polyuria improve our management of patients? ICIRS 2014. Neurourol Urodyn 2016;35:283-7.

15. Zumrutbas AE, Bozkurt AI, Tas E, Acar CI, Alkis O, Coban K, et al. Prevalence of lower urinary tract symptoms, overactive bladder and urinary incontinence in western Turkey: results of a population-based survey. Int J Urol 2014;21:1027-33.

16. Madersbacher S, Cornu JN. Nocturnal polyuria: it's all about definition, and be Patient! Eur Urol 2013;63:548-50.

17. Cornu JN, Abrams P, Chapple CR, Dmochowski RR, Lemack GE, Michel MC, et al. A contemporary assessment of nocturia: definition, epidemiology, pathophysiology, and management--a systematic review and meta-analysis. Eur Urol 2012;62:877-90.

18. Kirkland JL, Lye M, Levy DW, Banerjee AK. Patterns of urine flow and electrolyte excretion in healthy elderly people. Br Med J (Clin Res Ed) 1983;287:1665-7.

19. Robertson G, Rittig S, Kovacs L, Gaskill MB, Zee P, Nanninga J. Pathophysiology and treatment of enuresis in adults. Scand J Urol Nephrol Suppl 1999;202:36-8.

20. van Doorn B, Blanker MH, Kok ET, Westers P, Bosch JL. Once nocturia, always nocturia? Natural history of nocturia in older men based on frequency-volume charts: the Krimpen study. J Urol 2011;186:1956-61. 